\title{
Strain-Specific Regulation of Striatal Phenotype in Drd2-eGFP BAC Transgenic Mice
}

\author{
C. Savio Chan, ${ }^{1}$ Jayms D. Peterson, ${ }^{1}$ Tracy S. Gertler, ${ }^{1}$ Kelly E. Glajch, ${ }^{1}$ Ruth E. Quintana, ${ }^{1}$ Qiaoling Cui, ${ }^{1}$ Luke E. Sebel, ${ }^{1}$ \\ Joshua L. Plotkin, ${ }^{1}$ Weixing Shen, ${ }^{1}$ Myriam Heiman, ${ }^{2}$ Nathaniel Heintz, ${ }^{3}$ Paul Greengard, ${ }^{4}$ and D. James Surmeier ${ }^{1}$ \\ ${ }^{1}$ Department of Physiology, Northwestern University Feinberg School of Medicine, Chicago, Illinois 60611, ${ }^{2}$ Department of Brain and Cognitive Sciences, \\ Picower Institute of Learning and Memory, Massachusetts Institute of Technology, Broad Institute of Massachusetts Institute of Technology and Harvard, \\ Cambridge, Massachusetts 02142, and ${ }^{3}$ Laboratory of Molecular Biology, Howard Hughes Medical Institute, The Rockefeller University, and ${ }^{4}$ Laboratory of \\ Molecular and Cellular Neuroscience, The Rockefeller University, New York, New York 10065
}

Mice carrying bacterial artificial chromosome (BAC) transgenes have become important tools for neuroscientists, providing a powerful means of dissecting complex neural circuits in the brain. Recently, it was reported that one popular line of these mice-mice possessing a BAC transgene with a $\mathrm{D}_{2}$ dopamine receptor (Drd2) promoter construct coupled to an enhanced green fluorescent protein (eGFP) reporter-had abnormal striatal gene expression, physiology, and motor behavior. Unlike most of the work using BAC mice, this interesting study relied upon mice backcrossed on the outbred Swiss Webster (SW) strain that were homozygous for the Drd2-eGFP BAC transgene. The experiments reported here were conducted to determine whether mouse strain or zygosity was a factor in the reported abnormalities. As reported, SW mice were very sensitive to transgene expression. However, in more commonly used inbred strains of mice $(\mathrm{C} 57 \mathrm{BL} / 6, \mathrm{FVB} / \mathrm{N})$ that were hemizygous for the transgene, the Drd2-eGFP BAC transgene did not alter striatal gene expression, physiology, or motor behavior. Thus, the use of inbred strains of mice that are hemizygous for the Drd2 BAC transgene provides a reliable tool for studying basal ganglia function.

\section{Introduction}

Mice carrying engineered bacterial artificial chromosome (BAC) transgenes have become an important tool for neuroscience research (Gong et al., 2003, 2010). By inserting an expression cassette that contains the regulatory elements of a particular gene into a BAC vector, it has been possible to drive the expression of a genetically encoded fluorescent reporter (e.g., eGFP or tdTomato) or Cre recombinase in specific neuronal populations. Using this technology, the GENSAT (Gene Expression Nervous System Atlas; NIH-NINDS) project has generated $>1000$ mouse lines with targeted cellular expression of eGFP or Cre recombinase (Heintz, 2001; Gong et al., 2003; Siegert et al., 2009).

These mice have been a major resource to the neuroscience community and have enabled a wide range of previously unaddressable questions to be answered. For example, dopamine (DA) receptor $\mathrm{BAC}$ transgenic mice have been instrumental in

Received Jan. 16, 2012; revised April 29, 2012; accepted May 22, 2012.

Author contributions: C.S.C., T.S.G., and D.J.S. designed research; C.S.C., J.D.P., T.S.G., R.E.Q., Q.C., L.E.S., J.L.P., and W.S. performed research; C.S.C., J.D.P., T.S.G., R.E.Q., Q.C., L.E.S., and J.L.P. analyzed data; C.S.C., J.D.P., T.S.G., K.E.G., M.H., N.H., P.G., and D.J.S. wrote the paper.

This work was supported by the Summer Fellowship Program from American Parkinson Disease Association Research (T.S.G.), Summer Fellowship from Parkinson Disease Foundation (Q.C., R.E.Q.), a CHDI contract (D.J.S.), National Institutes of Health Grants NS069777 and NS069777-S1 (C.S.C.), and NS34696 (D.J.S.). We thank Sasha Ulrich, Karen Saportio, Daniel Kelver, Yu Chen, Lisa Fisher, John Linardakis, and Dr. Craig Weiss for their technical assistance.

The authors declare no competing financial interests.

Correspondence should be addressed to D. James Surmeier, Department of Physiology, Feinberg School of Medicine, Northwestern University, Chicago, IL 60611. E-mail: j-surmeier@northwestern.edu.

DOI:10.1523/JNEUROSCI.0229-12.2012

Copyright $\odot 2012$ the authors $\quad 0270-6474 / 12 / 329124-09 \$ 15.00 / 0$ allowing neurophysiologists and neuroanatomists to interrogate the two principal populations of spiny projection neurons (SPNs) in the striatum. Although these two populations play very different functional roles in the basal ganglia (Albin et al., 1989, 1995; DeLong, 1990), they are intermingled and have similar somatodendritic morphology, making them impossible to reliably distinguish visually. One distinguishing feature of these two populations is their expression of DA receptors. SPNs that project primarily to the substantia nigra, so-called direct-pathway SPNs (dSPNs), express the Drd1a (DA D 1 receptor), whereas SPNs that project to the globus pallidus, so-called indirect-pathway SPNs (iSPNs), express the Drd2 (DA $\mathrm{D}_{2}$ receptor). BAC transgenic mice in which GFP expression is driven either by a Drd1a or a Drd2 regulatory elements construct allow the visual identification of these SPNs in either fresh or fixed tissue, providing an enormous experimental advantage.

The utility of these mice depends upon the assumption that the transgene itself has little or no effect on phenotype. However, there are situations in which this assumption could be invalid. For example, the BAC construct invariably has sequences of unknown or poorly characterized function; if expressed, these sequences could alter cellular phenotype. In addition, chromosomal integration of the BAC construct could have effects on native gene expression that are independent of the transgene itself. Both of these effects could be sensitive to transgene copy number. As a consequence, BAC transgenic mice should be used with circumspection.

Recently, Kramer et al. (2011) reported that Swiss Webster (SW) mice that were homozygous for the Drd2-eGFP BAC trans- 
gene had an altered phenotype. In particular, they found significant abnormalities in the release of DA and in the response to cocaine administration. Given the growing use of these mice, we felt it was important to pursue these interesting findings. Although we were able to reproduce their observations in hemizygous SW mice, we did not find detectable changes in striatal gene expression, striatal physiology, or motor behavior in hemizygous $\mathrm{FVB} / \mathrm{N}$ or $\mathrm{C} 57 \mathrm{BL} / 6$ Drd2-eGFP transgenic mice.

\section{Materials and Methods}

Animals and genotyping. All experiments detailed are in accord with the Northwestern University Animal Care and Use Committee, and are in compliance with the NIH Guide to the Care and Use of Laboratory Animals. Unless otherwise noted, all experiments were conducted with Drd2-eGFP BAC transgenic mice on an FVB/NJ (inbred; The Jackson Laboratory), C57BL/6J (inbred; The Jackson Laboratory), and Swiss Webster (outbred; Taconic Farms) backgrounds. The original founder animals were a gift from Drs. N. Heintz and P. Greengard (The Rockefeller University, New York, NY). They were generated by injection of a modified BAC (containing eGFP under the regulatory elements of the Drd2 gene) into pronuclei of $\mathrm{FVB} / \mathrm{N}$ fertilized oocytes. Subsequently, zygotes were injected into pseudopregnant female Swiss Webster (an outbred strain from Taconic) (Gong et al., 2010). All Drd2-eGFP BAC transgenic mice in this study were backcrossed with wild-type inbred breeders for at least seven to nine generations to create hemizygote $\mathrm{FVB} / \mathrm{N}$ and C57BL/6 animals. The FVB/N line was outcrossed with the Swiss Webster animals for up to two generations for this study. All animals included in this study were males (unless otherwise indicated) between 3 and 5 weeks of age and housed and bred in the same environment. Transgene copy number was confirmed with tail biopsy using real-time quantitative PCR (with primers direct against the chloramphenicol-resistance gene of the BAC vector and Gapdh). Comparison was made using $\Delta \Delta \mathrm{CT}$ method (see below) with known standards.

Chronic DA depletion. Unilateral lesion of the nigrostriatal system was produced by 6-hydroxydopamine (6-OHDA) injection into the medial forebrain bundle (MFB) (Glajch et al., 2012). In brief, mice at postnatal day 28-32 were anesthetized with a mixture of ketamine $(50 \mathrm{mg} / \mathrm{kg}$, i.p.) and xylazine $(4.5 \mathrm{mg} / \mathrm{kg}$, i.p.). After immobilization on a stereotaxic frame (David Kopf Instruments) with a Cunningham adaptor (Harvard Apparatus), a hole was drilled ( $\sim 1 \mathrm{~mm}$ diameter) at $0.7 \mathrm{~mm}$ posterior and $1.1 \mathrm{~mm}$ lateral to bregma for injection into the MFB (0.7 AP, 1.1 ML, 4.8 DV). One microliter of 6-OHDA HCl (Sigma-Aldrich) was dissolved at a concentration of $7.5 \mu \mathrm{g} / \mu \mathrm{l}$ saline with $0.02 \%$ ascorbate and injected using a calibrated glass micropipette (Drummond Scientific), at a rate of $0.02 \mu \mathrm{l} / \mathrm{min}$ and at a depth of $4.8 \mathrm{~mm}$ from the surface of the skull. The micropipette was left in situ for another $30 \mathrm{~min}$ after the injection to maximize tissue retention of 6-OHDA and decrease capillary spread upon pipette withdrawal. Electrophysiological experiments were performed 3-4 weeks later.

Drd2 antagonist treatment. Eticlopride $\mathrm{HCl}(1 \mathrm{mg} / \mathrm{kg}$; Tocris Bioscience) was dissolved in sterile PBS and stored at $4^{\circ} \mathrm{C}$. Homozygous Drd2eGFP FVB/N mice (3-4 week) were injected intraperitoneally once daily for $14 \mathrm{~d}$. Animals were killed for recording $24 \mathrm{~h}$ after the last injection to ensure the clearance of eticlopride and its metabolites from the brain.

Behavioral testing. An open-field arena $(56 \times 56 \mathrm{~cm})$ was used for measuring non-reinforced ambulatory behavior of animals (4-5 weeks of age). Each arena was cleaned with disinfectant before the testing of each subject. Behavioral assessment of subjects were performed between 3:00 and 6:00 P.M. with the ambient light set at 35 lux. An individual mouse was placed in the center of the arena, and its ambulation and exploratory activity were recorded by a CCD camera connected to a personal computer. Video tracking of animals was performed for $20 \mathrm{~min}$ using LimeLight2 (Coulbourn Instruments) at rate of 3.75 frames per second. The arena contained a $10 \times 10$ grid block on the bottom surface to allow off-line analysis of the animals' movement in specific regions of the arena. In each session, the total distance traveled as well as the percentage of time/distance within different parts of the arena were re- corded. Behavioral assays were performed at the Northwestern University Behavioral Phenotyping Core Facility.

Protein assays. Western blotting procedures were similar to those previously described (Chan et al., 2011). In brief, membrane protein fractions were prepared by lysis of tissue in buffer containing $10 \mathrm{mM}$ HEPES, $\mathrm{pH} 7.4$, and $320 \mathrm{~mm}$ sucrose, followed by brief centrifugation to remove nuclei and insoluble material. After centrifugation at $16,000 \times g$, the pellet was resuspended by gentle rocking at $4^{\circ} \mathrm{C}$ in TEEN-Tx $(0.1 \mathrm{M}$ Tris, $1 \mathrm{~mm}$ EDTA, $1 \mathrm{~mm}$ EGTA, and 1\% Triton X-100). Protein extracts were resolved by SDS-PAGE and transferred to polyvinylidene difluoride membranes. Western blotting was performed using Drd2 primary antibody at a concentration of $1 \mu \mathrm{g} / \mathrm{ml}$ (a gift from Ryuichi Shigemoto, National Institute for Physiological Sciences, Okazaki, Japan).

Expression profiling. Quantitative PCR ( $\mathrm{PPCR}$ ) was used to determine the abundance of transcripts of interest with procedures similar to that described previously (Chan et al., 2011). In brief, striata were microdissected in ice-cold artificial CSF (aCSF) from a series of $300 \mu \mathrm{m}$ tissue slices. Total RNA was isolated using RNeasy micro kit (QIAGEN). cDNA was synthesized using qScript cDNA Supermix (Quanta Biosciences). Real-time PCR was performed using Fast SYBR Mastermix (Applied Biosystems) on a StepOnePlus thermocycler (Applied Biosystems). The thermal cycling conditions comprised an initial denaturing step at $95^{\circ} \mathrm{C}$ for $20 \mathrm{~s}$, and 40 cycles at $95^{\circ} \mathrm{C}$ for $3 \mathrm{~s}, 60^{\circ} \mathrm{C}$ for $30 \mathrm{~s}$. The PCR cycle threshold (Ct) values were measured within the exponential phase of the PCR using StepOnePlus software, version 2.1 (Applied Biosystems). A correction was performed using a passive reference dye (Rox) present in the PCR master mix. Reactions with any evidence of nonspecificity (i.e., low melting temperatures or multiple peaks in melting point analysis) were excluded from the analysis. A relative quantification method (i.e., $\Delta \Delta$ CT method) was used to quantify differences in gene expression level (Schmittgen and Livak, 2008). To increase accuracy of the gene expression analysis, a panel of reference genes (Atp5b, Cyc1, Eef1e1, Gapdh, Gusb, H2afz, Hmbs, Sdha, Uchl1) were included to establish an ensemble reference-weighted $\mathrm{Ct}$ values based on the stability of each reference gene were calculated from established algorithms (Vandesompele et al., 2002; Andersen et al., 2004; Pfaffl et al., 2004; Silver et al., 2006), as described in Equations 1-3:

$$
\begin{gathered}
R=\frac{\frac{1}{r v_{\mathrm{RG}_{i}}}}{\sum_{i=1}^{n} \frac{1}{r v_{\mathrm{RG}_{i}}}} \\
\alpha_{\mathrm{RG}_{i}}=\frac{\left[R_{1}+R_{2}+R_{3}+R_{4}\right]}{4}, \\
\text { Weighted } \mathrm{Ct}=\sum_{i=1}^{n}\left(\alpha_{\mathrm{RG}_{i}} * \mathrm{Ct}_{\mathrm{RG}_{i}}\right) .
\end{gathered}
$$

$R$ is a relative value that incorporates the rank values of all the reference genes for a particular algorithm. $\alpha_{\mathrm{RG}}$ represents the average $R$ value calculated using four different algorithms. $\mathrm{Ct}_{\mathrm{RG}}$ is the $\mathrm{Ct}$ value of a reference gene for an individual sample. Experiments for each gene of interest were run in triplicate. Desalted primers were custom synthesized (Invitrogen) and intron-spanning whenever possible. No-template and no-reverse-transcriptase control assays produced negligible signals, suggesting that primer dimer formation and genomic DNA contamination effects were small. The mRNA levels in each subgroup of samples were characterized by their median values. Results were presented as fold difference relative to their respective wild-type controls. Data are presented as median fold difference and median experimental error (SD) (Bookout et al., 2006). Statistical analysis (Mann-Whitney $U$ test) was performed. Differences between the genotypes were judged significant at confidence levels of $95 \%(p<0.05)$.

Electrophysiology. Mice (males; 3-5 weeks of age) were anesthetized with ketamine/xylazine and perfused transcardially with ice-cold aCSF containing the following (in mM): $125 \mathrm{NaCl}, 2.5 \mathrm{KCl}, 1.25 \mathrm{NaH}_{2} \mathrm{PO}_{4}, 2.0$ $\mathrm{CaCl}_{2}, 1.0 \mathrm{MgCl}_{2}, 25 \mathrm{NaHCO}_{3}$, and 12.5 glucose, bubbled continuously with carbogen $\left(95 \% \mathrm{O}_{2}\right.$ and $\left.5 \% \mathrm{CO}_{2}\right)$. The brains were rapidly removed, 


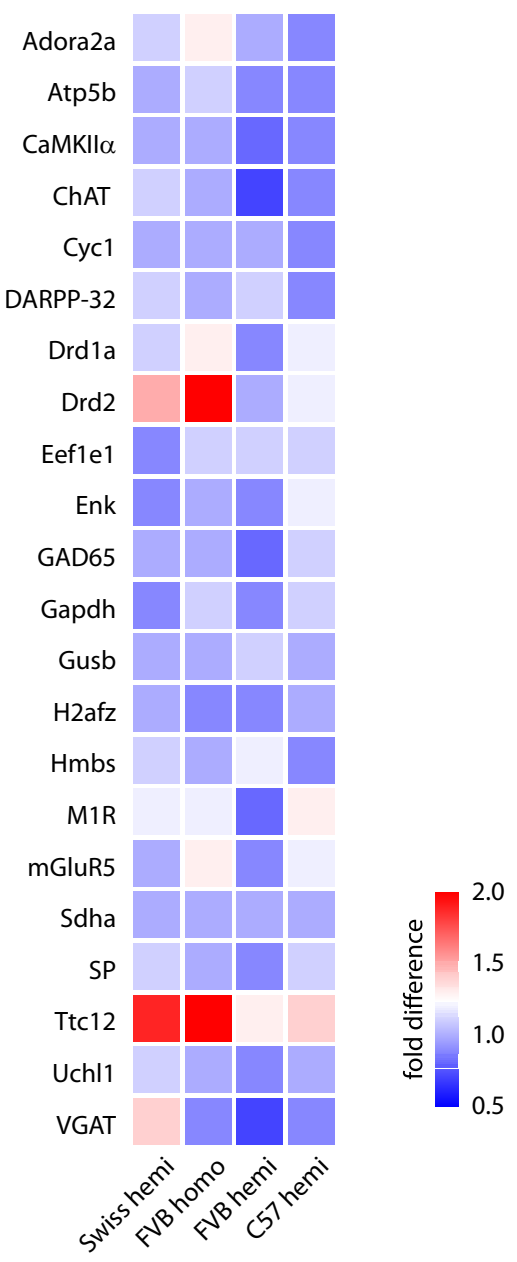

Figure 1. Drd2-eGFPBACtransgenic mice display modest alterations in gene expression that are strain and zygosity specific. qPCR analyses were performed on Drd2-GFP BAC mice of different genetic backgrounds and zygosity. Gene expression levels are presented relative to their respective wild-type controls. Multiple reference genes (Atp5b, Cyc1, Eef1e1, Gapdh, Gusb, H2afz, Hmbs, Sdha, and Uchl1) were included in the analyses to account for the differential transcript expression across mouse groups. Target genes with important functions in the striatum were chosen for expression analysis. Ttc12 is a passenger gene included in the Drd2-eGFP BAC construct. Note that Drd2 and Ttc12 expression were differentially regulated across different mouse groups.

glued to the stage of a slicer (Leica), and immersed in ice-cold aCSF. Striatal slices were cut at a thickness of $240-275 \mu \mathrm{m}$ and transferred to a holding chamber, where they were submerged in aCSF at $35^{\circ} \mathrm{C}$ for 30 $\mathrm{min}$, and returned to room temperature before recording. SPNs within the dorsal striatum were identified by their somatic morphological characteristics under infrared-differential interference contrast or Dodt-contrast optics. Somatic eGFP expression was verified using epifluorescence microscopy to confirm cell identity before breaking into whole-cell mode. Recordings were made at room temperature $\left(20-22^{\circ} \mathrm{C}\right)$ with patch electrodes $(1.5 \mathrm{~mm}$ outer diameter $)$ fabricated from filamented, thick-wall borosilicate glass (Sutter Instrument) pulled on a Flaming-Brown puller (Sutter) and fire polished immediately before use. Pipette resistance was typically $\sim 3-5 \mathrm{M} \Omega$. For current-clamp recordings, the internal solution consisted of the following (in $\mathrm{mM}$ ): 135 $\mathrm{KMeSO}_{4}, 5 \mathrm{KCl}, 10 \mathrm{Na}_{2}$-phosphocreatine, 5 EGTA, $0.5 \mathrm{CaCl}_{2}, 2 \mathrm{Mg}$ ATP, $0.5 \mathrm{Na}_{3}$-GTP, 5 HEPES, adjusted to $\mathrm{pH} 7.25-7.30$ with $\mathrm{KOH}, 300$ mOsm. The liquid junction potential in recordings was $\sim 7 \mathrm{mV}$ and was not corrected for. For voltage-clamp experiments, pipettes were filled with a $\mathrm{Cs}^{+}$-based internal solution containing the following (in $\mathrm{mm}$ ): $125 \mathrm{CsMeSO}_{3}, 5$ TEA-Cl, $10 \mathrm{Na}_{2}$-phosphocreatine, 5 HEPES, 0.25 EGTA, 2 Mg-ATP, 0.5 Na-GTP, 1 QX-314-Cl, adjusted to pH 7.25-7.30 with $\mathrm{CsOH}, 300 \mathrm{mOsm}$. Electrical stimulation $(200-400 \mu \mathrm{s})$ was per-
Table 1. Summary of striatal gene expression (fold change) in mice of varying strains and zygosity for Ddr2-eGFP BAC transgene

\begin{tabular}{lllll}
\hline & SW hemi & FVB/N homo & FVB/N hemi & C57BL/6 hemi \\
\hline Adora2a & 1.1 & $1.3^{* *}$ & 1.0 & 0.9 \\
Atp5b & 1.0 & 1.1 & 0.9 & 0.9 \\
CaMKIlla & 1.0 & 1.0 & $0.8^{*}$ & 0.9 \\
ChAT & 1.1 & 1.0 & 0.7 & 0.9 \\
Cyc1 & 1.0 & 1.0 & 1.0 & 0.9 \\
Darpp32 & 1.1 & 1.0 & 1.1 & 0.9 \\
Drd1a & 1.1 & $1.3^{*}$ & 0.9 & 1.2 \\
Drd2 & $1.5^{*}$ & $2.0^{* *}$ & 1.0 & 1.2 \\
Eef1e & 0.9 & 1.1 & 1.1 & 1.1 \\
Enk & 0.9 & 1.0 & 0.9 & 1.2 \\
Gad65 & 1.0 & 1.0 & 0.8 & 1.1 \\
Gapdh & 0.9 & 1.1 & 0.9 & 1.1 \\
Gusb & 1.0 & 1.0 & 1.1 & 1.0 \\
H2afz & 1.0 & 0.9 & 0.9 & 1.0 \\
Hmbs & 1.1 & 1.0 & 1.2 & 0.9 \\
M1R & 1.2 & 1.2 & 0.8 & 1.3 \\
mGluR5 & 1.0 & 1.3 & 0.9 & 1.2 \\
Sdha & 1.0 & 1.0 & 1.0 & 1.0 \\
SP & 1.1 & 1.0 & 0.9 & 1.1 \\
Ttc12 & $1.9^{*}$ & $2.1^{* *}$ & $1.3^{*}$ & 1.4 \\
Uchl1 & 1.1 & 1.0 & 0.9 & 1.0 \\
VGAT & $1.4^{*}$ & 0.9 & 0.7 & 0.9 \\
\hline * $<0.05 ; d$ & & & &
\end{tabular}

${ }^{*} p<0.05$; data analyzed using Mann-Whitney statistical test.

${ }^{* *} p<0.01$; data analyzed using Mann-Whitney statistical test.

formed using parallel bipolar tungsten electrodes (Frederick Haer) placed in the layer V-VI of the cortex. Somatic whole-cell patch-clamp recordings were obtained with an amplifier (Molecular Devices). The signal for voltage-clamp recordings was filtered at $1 \mathrm{kHz}$ and digitized at $10 \mathrm{kHz}$ with a digitizer (Molecular Devices). For current-clamp recordings, the amplifier bridge circuit was adjusted to compensate for electrode resistance and subsequently monitored.

Spine counts. SPNs in tissue slices (as described above) were loaded with Alexa Fluor $594(50 \mu \mathrm{M})$ through the patch pipette. All experiments were performed at room temperature. Images were acquired with a $60 \times / 1.00 \mathrm{NA}$ water-immersion lens (Olympus). The twophoton excitation source was a Chameleon-Ultra2 tunable laser system $(680-1080 \mathrm{~nm})$ using titanium:sapphire gain medium with all-solid-state active components and a computer-optimized algorithm to ensure reproducible excitation wavelength, average power, and peak power (Coherent Laser Group). Optical signals were acquired using $810 \mathrm{~nm}$ excitation beam ( $80 \mathrm{MHz}$ pulse repetition frequency and $250 \mathrm{fs}$ pulse duration) to excite Alexa 594. The fluorescence emission was collected by external or non-descanned photomultiplier tubes (PMTs). The red fluorescence $(580-640 \mathrm{~nm})$ was collected by a multi-alkalicathode (S-20) PMT. Measurements were taken in a sample plane along dendritic segments ( $>50 \mu \mathrm{m}$ from the soma). On average, $\sim 80$ spines were counted per dendritic segments; up to three measurements were performed on each cell.

Data and statistical analyses. Curve fitting and data analyses were done with ClampFit 9 (Molecular Devices), Igor Pro 6.0 (WaveMetrics), MATLAB 7.12 (MathWorks), MiniAnalysis 6.0.3 (Synaptosoft), and Prism 5 (GraphPad). Box plots were used for graphic representation: the central line represents the median, the edges represent the interquartile ranges, and the whiskers represent the overall distribution. Asterisks indicate $95 \%$ confidence $(p<0.05)$ unless otherwise noted. Normal distributions were not assumed regardless of sample size or variance. Pairwise comparisons for unrelated samples were performed using a Mann-Whitney $U$ test with a threshold of $p<0.05$ for significance. Kruskal-Wallis one-way ANOVA was performed for group comparisons with a threshold of $p<0.05$. Frequency-intensity $(F-I)$ curves were analyzed with two-way repeated-measures ANOVA, with SPN type or treatment group and current injection as independent variables. Group main effect between SPN type or treatment group is reported. Significance was set as $\alpha=0.05$. 
A

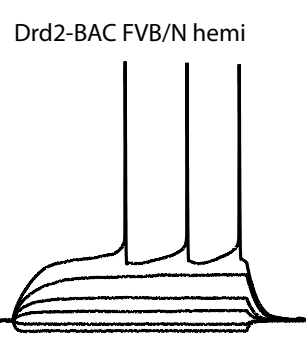

dSPN

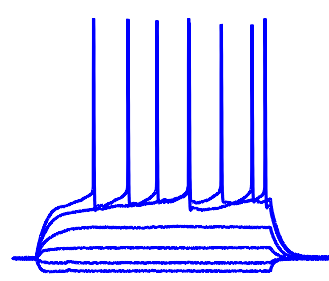

iSPN
B

Drd2-BAC FVB/N homo

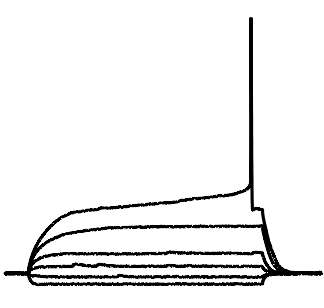

dSPN

C

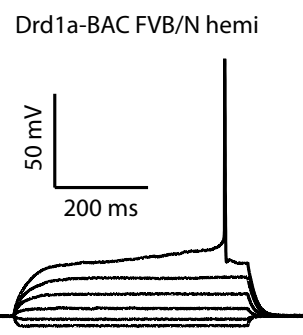

dSPN

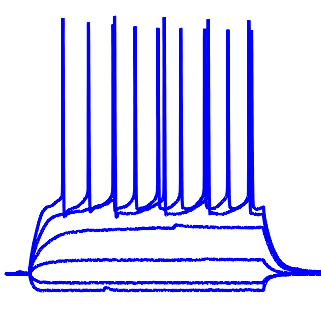

iSPN

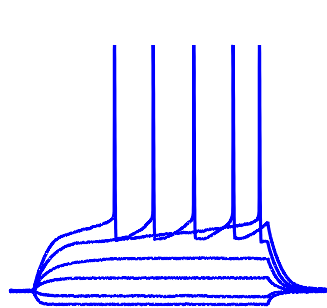

iSPN

D

Drd2-BAC C57BL/6 hemi

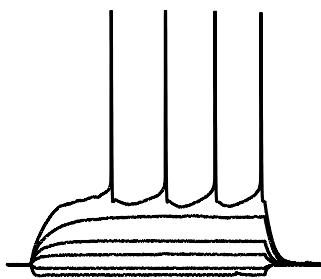

dSPN

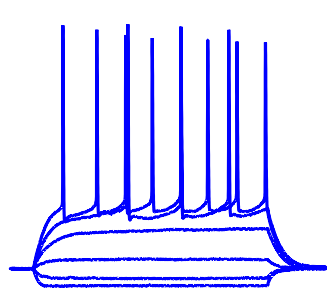

iSPN
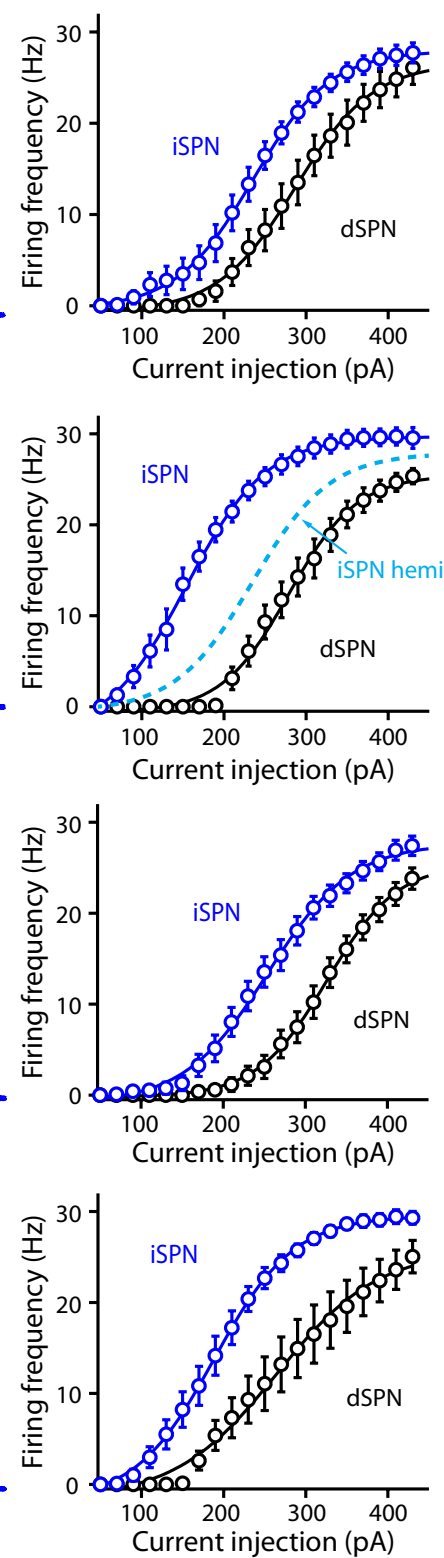

$E$ Drd2-BAC Swiss Webster hemi

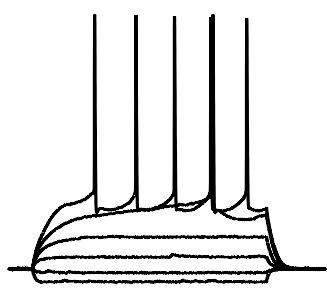

dSPN

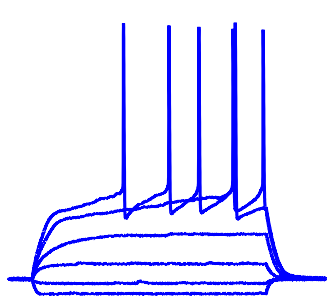

iSPN

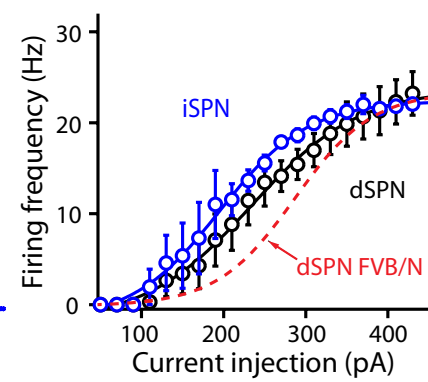

Figure 2. The dichotomy in the intrinsic properties of striatal SPNs is preserved in the Drd2-eGFP BAC transgenic mice. $\boldsymbol{A}-\boldsymbol{E}$, Left, Sample current-clamp recordings showing differences in the excitability of dSPNs and iSPNs in brain slices from different strains of mice of varying zygosity for the BAC transgene. Right, Pooled frequency - current plots for each condition. Note the clear dichotomy in excitability except in the case of SW mice.

\section{Results}

Analysis of gene expression in Drd2-eGFP BAC mice

The expression cassette in the BAC vector used in creating the Drd2-eGFP line was constructed by the insertion of a polyadenylated reporter gene (i.e., eGFP) into the Drd2 locus imme- diately downstream of the ATG translation initiation codon. The removal of the $\mathrm{Drd} 2$ coding sequence downstream from the initiation codon rendered no functional Drd2 RNA or protein expression from the BAC vector. Surprisingly, the study by Kramer et al. (2011) found that there was overexpression of the $\operatorname{Drd} 2$ gene, in SW mice that were homozygous for the Drd2-eGFP transgene. To determine whether zygosity was a factor in this effect, quantitative real-time PCR (qPCR) profiling for 21 transcripts was performed on striatal tissue derived from four different lines of mice of varying strain and zygosity for the Drd2-eGFP transgene (Fig. 1 , Table 1). In hemizygous SW mice, there was a modest ( $\sim 1.5$-fold), but significant elevation in Drd2 mRNA $(p<0.05$, Mann-Whitney $U$ test). However, in hemizygous $\mathrm{C} 57 \mathrm{BL} / 6$ and $\mathrm{FVB} / \mathrm{N}$ mice, there was no detectable change in Drd2 expression level ( $p>0.05$, Mann-Whitney $U$ test). In homozygous $\mathrm{FVB} / \mathrm{N}$ mice, however, $D r d 2$ expression was significantly elevated ( $\sim 2$-fold) ( $p<0.05$, Mann-Whitney $U$ test). This was not a consequence of amplification of the truncated Drd2 transgene in the BAC vector, as primers were directed against only the full-length $\operatorname{Drd} 2$ sequence. This analysis also found that in homozygous $\mathrm{FVB} / \mathrm{N}$ mice there was a concomitant upregulation of Drdla and Adora2a (adenosine A2a receptor) (Fig. 1) $(p<0.05$, Mann-Whitney

$U$ test).

It has been suggested that Ttc12 is a "passenger" gene in the Drd2-eGFP BAC construct that might alter cellular phenotype (Kramer et al., 2011). If this were true, zygosity should dictate Ttc12 RNA levels. Although the abundance of Ttc12 RNA was correlated with zygosity, its expression also varied with mouse strain (Fig. 1). At this point, we do not know whether this has any causal effect on the phenotype of the striatum.

\section{Analysis of striatal physiology in Drd2-eGFP BAC mice}

To determine whether the Drd2-eGFP transgene altered striatal physiology, wholecell recordings were made from iSPNs and dSPNs in brain slices from three different strains of transgenic mice.

First, the intrinsic excitability of each population of SPNs was assessed by constructing plots of spike rate as a function of current injected through a somatic electrode; these plots are called frequency-intensity $(F-I)$ curves. Several groups have reported that iSPNs are more excitable than dSPNs, as manifested by $F-I$ curves that are shifted to the left along the current axis (Kreitzer and Malenka, 2007; Ade et al., 2008; Gertler et al., 2008). 
Table 2. Statistical summary of the comparison between SPN excitability in mice of varying strains and zygosity for BAC transgenes: dSPNs

\begin{tabular}{llllll}
\hline dSPNs & Drd1a FVB/N hemi $(n=22)$ & $\operatorname{Drd2}$ FVB/N hemi $(n=12)$ & $\operatorname{Drd2~FVB/N~homo~}(n=15)$ & $\operatorname{Drd2~C57BL/6~hemi~}(n=16)$ & $\operatorname{Drd2~SW~hemi~}(n=7)$ \\
\hline Drd1a FVB/N hemi $(n=22)$ & - & 0.071 & $0.035^{*}$ & 0.056 & $0.008^{*}$ \\
Drd2 FVB/N hemi $(n=12)$ & 0.071 & - & 0.989 & 0.759 & 0.311 \\
Drd2 FVB/N homo $(n=15)$ & $0.035^{*}$ & 0.989 & - & 0.732 & 0.748 \\
Drd2 C57BL/6 hemi $(n=16)$ & 0.056 & 0.759 & 0.732 & - & 0.616 \\
Drd2 SW hemi $(n=7)$ & $0.008^{*}$ & 0.311 & 0.748 & 0.616 & - \\
\hline
\end{tabular}

Data analyzed using two-way repeated-measures ANOVA, group main effect, $p$ value reported. ${ }^{*} p<0.05$.

Table 3. Statistical summary of the comparison between SPN excitability in mice of varying strains and zygosity for BAC transgenes: iSPNs

\begin{tabular}{lccccc}
\hline iSPNs & Drd1a FVB/N hemi $(n=22)$ & $\operatorname{Drd2}$ FVB/N hemi $(n=19)$ & $\operatorname{Drd2~FVB/N~homo~}(n=14)$ & $\operatorname{Drd2}$ C57BL/6 hemi $(n=21)$ & $\operatorname{Drd2~SW~hemi~}(n=5)$ \\
\hline Drd1a FVB/N hemi $(n=22)$ & - & 0.181 & $<0.001^{*}$ & $<0.001^{*}$ & $0.005^{*}$ \\
Drd2 FVB/N hemi $(n=19)$ & 0.181 & - & $<0.001^{*}$ & $0.029^{*}$ & 0.937 \\
Drd2 FVB/N homo $(n=14)$ & $<0.001^{*}$ & $<0.001^{*}$ & - & - & $0.001^{*}$ \\
Drd2 C57BL/6 hemi $(n=21)$ & $<0.001^{*}$ & $0.005^{*}$ & $<.029^{*}$ & $0.021^{*}$ & $-0.021^{*}$ \\
Drd2 SW hemi $(n=5)$ & 0.36 & 0.937 & $<0.001^{*}$ & -
\end{tabular}

Data analyzed using two-way repeated-measures ANOVA, group main effect, $p$ value reported. ${ }^{*} p<0.05$.

This dichotomy was preserved in hemizygous and homozygous Drd2-eGFP BAC FVB/N mice (Drd2 FVB/N hemi: iSPNs, $n=19$; dSPNs, $n=12$; Drd2 FVB/N homo: iSPNs, $n=14$; dSPNs, $n=15$; group main effect, $p<0.01$, two-way repeated measures ANOVA) (Fig. 2A,B). However, in homozygous mice, the excitability of iSPNs neurons was significantly increased compared with iSPNs in hemizygous FVB/N mice (Tables 2, 3; group main effect, $p<0.001$, two-way repeated measures ANOVA) (Fig. $2 B$ ); in this figure, the $F-I$ curve for the hemizygous mice is plotted as a dashed line for comparison. To determine whether the dichotomy was an artifact of the Drd2-eGFP transgene, GFPpositive and -negative SPNs were sampled from hemizygous Drdla-eGFP BAC transgenic FVB/N mice, which have no apparent adaptation in response to transgene expression (Ade et al., 2011). In these mice, GFP-negative neurons were assumed to be iSPNs, as shown by previous work (Gertler et al., 2008). The F-I curves of dSPNs and iSPNs in these mice were very similar to those in hemizygous Drd2eGFP mice (Drdla FVB/N hemi: iSPNs, $n=22$; dSPNs, $n=22$; group main effect, $p>0.05$, two-way repeated-measures ANOVA) (Fig. 2C; Tables 2, 3), arguing that the dichotomy was not an artifact and that, in hemizygous $\mathrm{FVB} / \mathrm{N}$ mice, the transgene had no effect on intrinsic excitability.

To pursue the potential effects of mouse strain, hemizygous C57BL/6 and SW mice were also examined. In hemizygous C57BL/6 mice, the excitability of dSPNs and iSPNs was significantly different (Drd2 C57BL/6 hemi: iSPNs, $n=21$; dSPNs, $n=16$; group main effect, $p<0.001$, two-way repeated measures ANOVA) - as found in hemizygous Drd2-eGFP FVB/N mice (Fig. 2D; Tables 2, 3). In contrast, there was not a significant difference between dSPNs and iSPNs in hemi-iSPN

hemi-iSPN

homo-iPSN

\section{A Corticostriatal EPSCs}
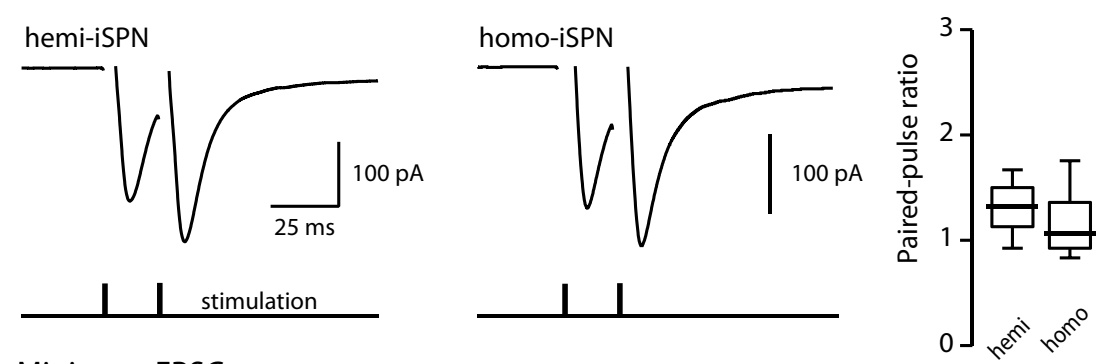

B Miniature EPSCs
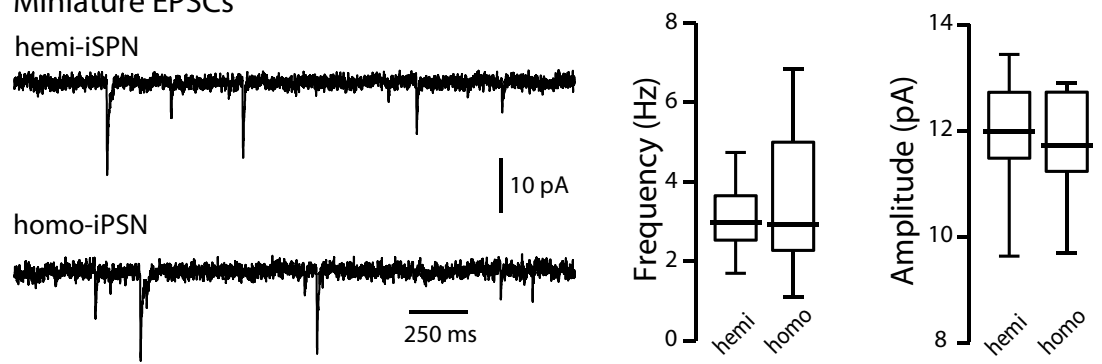

\section{2PSLM spine imaging}
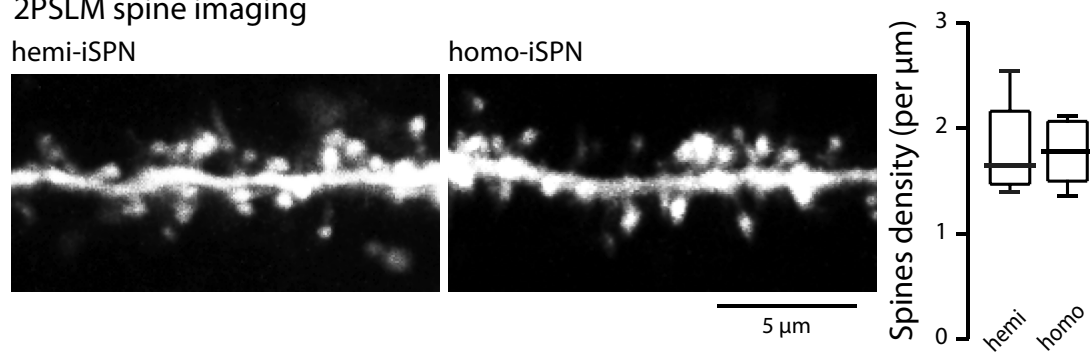

Figure 3. Synaptic properties of corticostriatal input to SPNs are not altered by Drd2-eGFP BAC transgene. Physiological and anatomical properties of corticostriatal iSPNs from hemizygous and homozygous Drd2-eGFP BAC transgenic on an FVB/N background were measured. $A$, Corticostriatal glutamatergic synaptic responses in iSPNs evoked by paired-pulse electrical stimulation (delivered at $50 \mathrm{~Hz}$ ) at the times shown at the bottom. Right, Box plot of paired-pulse ratios from the two genotypes revealed the responses were identical. $\boldsymbol{B}$, Representative traces of $\mathrm{mEPSC}$ in iSPNs. No difference in the frequency or amplitude of $\mathrm{mEPSC}$ was noted, as shown in box plots on the right. C, Two-photon spine imaging of isPNs in brain slices from Drd2-eGFP BAC transgenic mice. No significant difference in the spine density was found as shown by the box plot on the right.

hemizygous Drd2-eGFP SW mice (SW hemi: iSPNs, $n=5$; dSPNs, $n=7$; group main effect, $p>0.05$, two-way repeatedmeasures ANOVA) (Fig. 2 E; Tables 2, 3). This phenotypic difference was unlikely to have been a consequence of elevated $\operatorname{Drd} 2$ 
expression, however, as this should have increased the excitability of iSPNs and these cells were very similar in SW and FVB/N mice (Tables 2, 3; group main effect, $p>0.05$, two-way repeated measures ANOVA) (Fig. 2, compare $E, A$ ). Rather, the similarity in SW SPNs was attributable to a relative shift in the excitability of dSPNs (see dotted red line for comparison), suggesting that strain differences, not the transgene, was responsible.

To provide an assay of network physiology to complement the assessment of intrinsic excitability, the synaptic connectivity between cortical pyramidal neurons and SPNs was examined. Both short- and long-term plasticity of this synapse is controlled by DA and potentially sensitive to alterations in Drd2 expression (Gerfen and Surmeier, 2011). Short-term excitability of this synapse was examined using a paired-pulse protocol (Zucker and Regehr, 2002; Branco and Staras, 2009). There were no detectable differences in the paired-pulse ratio of corticostriatal synapses on iSPNs, measured at $50 \mathrm{~Hz}$ (Fig. 3A), as a function of strain or zygosity of animals (FVB/N homo, median, 1.070, $n=17$; FVB/N hemi, median, $1.325, n=12$; C57BL/6 hemi, median, $1.465, n=14 ; p>0.05$, Kruskal-Wallis test). Similarly, there were no differences in the frequency (FVB/N homo, median, $2.92 \mathrm{~Hz}, n=11 ; \mathrm{FVB} / \mathrm{N}$ hemi, median, $2.98 \mathrm{~Hz}, n=7$; C57BL/6 hemi, median, $2.77 \mathrm{~Hz}, n=8$ ) or amplitude (FVB/N homo, median, $11.73 \mathrm{pA}, n=11 ; \mathrm{FVB} / \mathrm{N}$ hemi, median, $11.99 \mathrm{pA}, n=7$; C57BL/6 hemi, median, $11.63 \mathrm{pA}$, $n=8)$ of miniature EPSCs (mEPSCs) in any of these lines ( $p>$ 0.05, Kruskal-Wallis test) (Fig. $3 B$ ), arguing that the release probability at glutamatergic synapses, as well as their number, was unaltered by expression of the Drd2-eGFP transgene. In agreement with this inference, in iSPNs the density of dendritic spines-membrane specializations in which glutamatergic synapses are formed-was not affected by strain or transgene zygosity (SW hemi, median, 1.85 spine $/ \mu \mathrm{m}, n=8$; FVB/N homo, median, 1.78 spine/ $\mu \mathrm{m}, n=5$; FVB/N hemi, median, 1.64 spine/ $\mu \mathrm{m}, n=5)(p>0.05$, Kruskal-Wallis test) (Fig. $3 C)$.

\section{Cellular effects of persistent alterations in Drd2 signaling}

The data from homozygous FVB/N suggest that an elevation of Drd2 signaling can decrease the intrinsic excitability of iSPNs. To test this hypothesis, homozygous $\mathrm{FVB} / \mathrm{N}$ mice were subjected to two manipulations aimed at decreasing Drd2 activity. First, homozygous Drd2-eGFP mice were depleted of dopamine by the injection of the toxin 6-OHDA into the medial forebrain bundle (Glajch et al., 2012); these lesions deprived the striatum of $>90 \%$ of its dopaminergic innervation. Three to 4 weeks after this lesion, iSPNs were recorded in brain slices from these mice and unlesioned controls. As predicted, the $F-I$ curves of iSPNs in dopamine-depleted mice were shifted to the right along the current axis (naive: $n=35$; 6-OHDA: iSPNs, $n=14$; group main effect, $p<0.001$, two-way repeated measures ANOVA) (Fig. $4 A, B)$. To provide an alternative test, mice were administered the Drd2 antagonist eticlopride for 2 weeks. Again, iSPNs from treated mice were less excitable (naive: $n=35$; eticlopide: $n=16$; group main effect, $p<0.001$, two-way repeated measures ANOVA) and had $F-I$ curves that were shifted toward higher currents (Fig. 4A, bottom, dashed line). Together, these data show that alterations in Drd2 signaling can influence the intrinsic excitability of iSPNs, suggesting that the elevated intrinsic excitability of iSPNs in homozygous Drd2-eGFP BAC mice is attributable to their increased Drd2 expression.

\section{Analysis of behavior in Drd2-eGFP BAC mice}

Drd2 receptors are known to modulate motor function (Albin et al., 1989, 1995; Bergman et al., 1991; DeLong, 1990; Durieux et
A

B
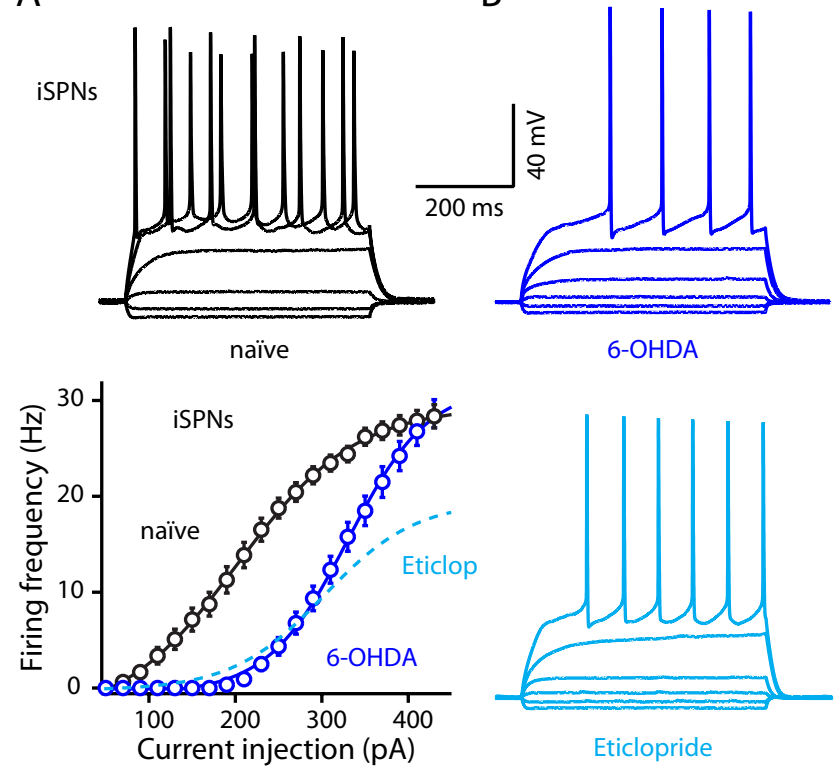

Figure 4. Intrinsic excitability of spiny projection neurons was regulated by dopamine. $\boldsymbol{A}$, Top, Representative current-clamp recordings showing the membrane potential of naive iSPNs in response to somatic current injection. Bottom, Frequency-current plots revealed a decrease (rightward shift) in iSPN excitability following chronic 6-OHDA lesions. The effect of subchronic Drd2 receptor blockade on the intrinsic excitability (dotted lines) was similar in iPSNs to that seen following 6-OHDA lesion. $\boldsymbol{B}$, Representative current-clamp recordings showing the membrane potential of iSPNs from 6-OHDA-lesioned and eticlopride-treated animals.

al., 2009). To assess non-reinforced ambulatory behavior of mice, an open-field test was used. There were no detectable effects of effects of the transgene on ambulatory activity in hemizygous $\mathrm{C} 57 \mathrm{BL} / 6, \mathrm{FVB} / \mathrm{N}$, and SW mice $(p>0.05$, Mann-Whitney $U$ test) (Fig. 5, Table 4). In contrast, in homozygous Drd2-eGFP $\mathrm{BAC}$ mice on the FVB/N background, there was a higher level of activity in the corner and periphery of the open field $(p<0.05$, Mann-Whitney $U$ test), although activity at the center of the arena was not significantly different (Table $4 ; p>0.05$, MannWhitney $U$ test). All mice spent the same percentage of time in all regions of the field ( $p>0.05$, Mann-Whitney $U$ test). These assays suggest that anxiety was not affected by transgene zygosity. To pursue this point, fecal droppings were counted (Taché et al., 1993; Henderson et al., 2004). In agreement with the open-field data, there was not a significant effect of strain or zygosity on this measure of anxiety (SW WT, median, 6.9, $n=8$; SW hemi, median, 4.3, $n=4$; FVB/N WT, median, 4.8, $n=9$; FVB/N homo, median, 5.4, $n=9$; FVB/N hemi, median, 6.1, $n=7$; C57BL/6 WT, median, 2.5, $n=6$; C57BL/6 hemi, median, $2.4, n=5)(p>$ 0.05, Mann-Whitney $U$ test).

\section{Discussion}

BAC transgenic mice have become important tools for neuroscientists, providing a powerful means of dissecting complex neural circuits in the brain (Gong et al., 2003). A critical assumption of studies using these mice is that the transgene does not alter cellular phenotype. Recent work has shown that, under some conditions, this assumption is violated (Kramer et al., 2011). Our studies corroborated these important findings. However, this effect was dependent upon mouse strain and transgene zygosity. In commonly used inbred strains of mice $(\mathrm{C} 57 \mathrm{BL} / 6, \mathrm{FVB} / \mathrm{N})$ that were hemizygous for the Drd2-eGFP BAC transgene, there were no significant changes in striatal gene expression, physiology, or 
A

VB

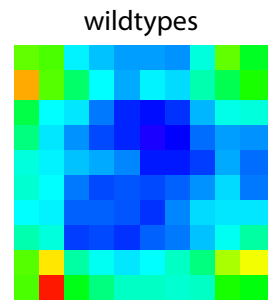

57

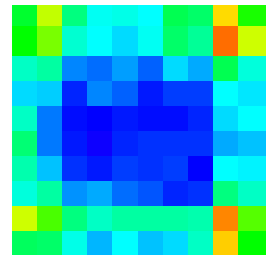

Swiss

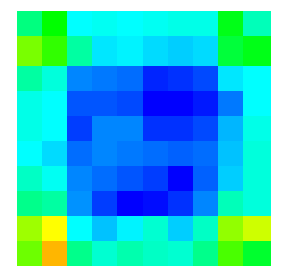

hemizygotes
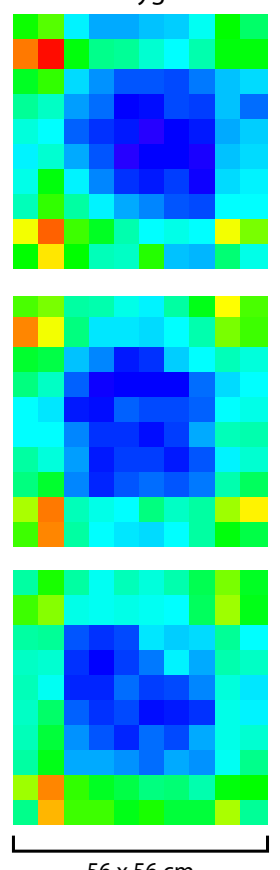

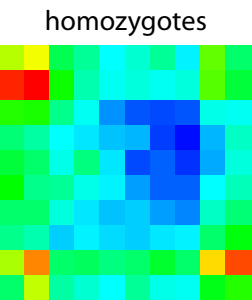

number of crossings

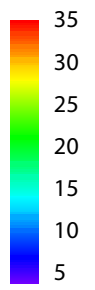

B
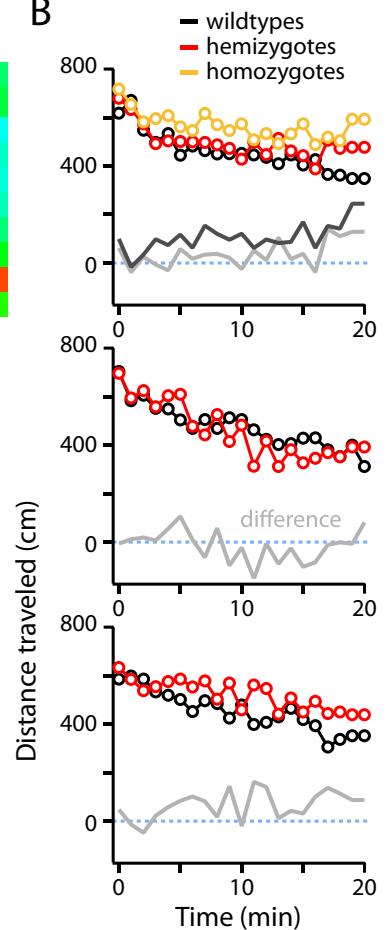

Figure 5. Ambulatory activity was unaltered in hemizygous Drd2-eGFP mice. $\boldsymbol{A}$, Heat maps derived from the total number of crossing across the open field within a 20 min testing session. Data were averaged between animals from the same cohort. No differences in the level of activity were noted between hemizygotes and their respective wild-type controls. In contrast, homozygous Drd2-eGFP FVB/N animals had elevated activity. Only males were included in this study, except for the Swiss Webster group in which both male and female subjects were used. No significant differences were noted between male and female Swiss Webster mice, so the data from both were pooled. $\boldsymbol{B}$, Activity measurements are plotted as distance traveled as a function of time. Note the elevated activity in the homozygous Drd2-eGFP FVB/N mice.

Table 4. Summary of open-field behavior in mice of varying strains and zygosity for Ddr2-eGFP BAC transgene

\begin{tabular}{|c|c|c|c|c|c|c|c|}
\hline & \multicolumn{3}{|l|}{$\mathrm{FVB} / \mathrm{N}$} & \multicolumn{2}{|c|}{ Swiss Webster } & \multicolumn{2}{|l|}{$\mathrm{C} 57 \mathrm{BL} / 6$} \\
\hline & wt & hemi & homo & wt & hemi & wt & hemi \\
\hline \multicolumn{8}{|c|}{ Total no. of crossings } \\
\hline Zone 1 & 94 & 94 & $112^{*}$ & 74 & 91 & 87 & 84 \\
\hline Zone 2 & 131 & 126 & $159^{*}$ & 104 & 115 & 117 & 111 \\
\hline Zone 3 & 33 & 28 & $52^{*}$ & 29 & 29 & 32 & 28 \\
\hline All zones & 262 & 252 & 320 & 209 & 230 & 234 & 224 \\
\hline Grid & 1530 & 1639 & 1761 & 1528 & 1775 & 1607 & 1592 \\
\hline \multicolumn{8}{|c|}{ Total distance (cm) } \\
\hline Zone 1 & 6233.96 & 7287.36 & 8257.11 & 6901.59 & 8311.27 & 7156.23 & 7083.50 \\
\hline Zone 2 & 2276.57 & 2062.23 & 2718.26 & 2111.83 & 2121.01 & 2182.49 & 2070.46 \\
\hline Zone 3 & 265.14 & 181.19 & 372.02 & 249.95 & 274.60 & 264.72 & 207.78 \\
\hline All zones & 8863.34 & $10,269.31$ & $11,436.79$ & 9235.51 & $10,918.57$ & 9422.52 & 9556.90 \\
\hline
\end{tabular}

${ }^{*} p<0.05$; data analyzed using Mann-Whitney statistical test.

motor behavior-justifying the continued use of these mice as reliable tools. This conclusion is similar to that arrived at by another group of investigators studying hemizygous Drd2-eGFP C57BL/6 mice (Nelson et al., 2012).

\section{The impact of Drd2-eGFP transgene depends upon zygosity and strain}

Our studies examined three different lines of mice-outbred $\mathrm{SW}$, inbred $\mathrm{FVB} / \mathrm{N}$, and inbred $\mathrm{C} 57 \mathrm{BL} / 6$ mice- of varying zygosity for the Drd2-eGFP BAC transgene. Examination of striatal gene expression, striatal physiology, and striatally determined behavior revealed that the consequences of transgene expression were dependent upon both strain and zygosity. In agreement with the report by Kramer et al. (2011), striatal Drd2 and Ttc12 mRNA levels were elevated in striata from hemizygous SW mice.
However, expression of none of the other 11 genes assayed was altered in these mice, except VGAT (vesicular GABA transporter). Striatal mRNA for Drd2 and Ttc12 were also elevated in homozygous FVB/N mice and, like SW mice, displayed abnormalities in striatal physiology and open-field behavior. Why Drd2 expression was upregulated in these mice is unclear; one possibility is that having extra copies of the Drd2 intron 2 sequence on the multicopy BAC array titrates out Freud-1 binding on the endogenous Drd2 gene, leading to increased expression of the endogenous gene (Rogaeva et al., 2007). This effect would have to have a sharp threshold, however, as hemizygous FVB/N and C57BL/6 mice did not display any significant differences in striatal gene expression, physiology, or striatally determined behavior attributable to the transgene.

The determinants of this strain-dependent variation in response are not clear. However, the impact of strain and subtle variation in gene expression on the response to dopaminergic signaling is very well documented. Differences between strains and rodent species have been described for exploratory and baseline locomotor activity (Miner, 1997; Brodkin et al., 1998; Zamudio et al., 2005; McNamara et al., 2006) and the response to direct and indirect dopaminergic receptor ligands (Severson et al., 1981; Sved et al., 1984; Sanghera et al., 1990; Erwin et al., 1993; Womer et al., 1994; Grahame and Cunningham, 1995; Castellano et al., 1996; Miner, 1997; Brodkin et al., 1998; Patel et al., 1998; Zocchi et al., 1998; He and Shippenberg, 2000; Fowler et al., 2001; McNamara et al., 2006). Differences have also been noted between strains and species in the expression of the DA transporter (Brodkin et al., 1998; Flores et al., 1998; Jiao et al., 2003; Morice et al., 2004; Zamudio et al., 2005; D'Este et al., 2007) and DA receptors (Boehme and Ciaranello, 1981; Severson et al., 1981; Erwin et al., 
1993; Ng et al., 1994; Flores et al., 1998; Zamudio et al., 2005; McNamara et al., 2006), as well as differences in DA metabolism (Severson et al., 1981; Sved et al., 1984; Sanghera et al., 1990; Zocchi et al., 1998; He and Shippenberg, 2000), DA cell number (Ross et al., 1976; Baker et al., 1980, 1983; Sved et al., 1984; D’Este et al., 2007), and DA signaling (Ng et al., 1994; Brodkin et al., 1998).

\section{Drd2 expression and behavioral phenotype}

Is the alteration in locomotor behavior with transgene expression attributable to a modest elevation in striatal Drd2 expression, as suggested by Kramer et al. (2011)? Although plausible based upon current models of striatal function, our studies raise doubts about this conclusion. In hemizygous mice from three different strains (SW, FVB/N, C57BL/6), there was no relationship between striatal Drd2 expression level and openfield behavior. While the Drd2 expression from the hemizygous $\mathrm{FVB} / \mathrm{N}$ and $\mathrm{C} 57 \mathrm{BL} / 6$ mice was normal, it was elevated in the hemizygous outbred SW. Our behavioral results are consistent with recent work by Nelson et al. (2012) reporting no behavioral abnormalities in hemizygous Drd2-eGFP C57BL/6 mice. Our results and those of Nelson et al. contrast slightly with those of Ade et al. (2011), who found a slight, but significant, elevation in the open-field activity of hemizygous Drd2-eGFP mice on a C57BL/6 background.

The basis for the hyperactivity in homozygous Drd2-eGFP $\mathrm{BAC} \mathrm{FVB} / \mathrm{N}$ mice is not clear. It is not readily attributable to an elevation in Drd2 expression. In these mice, not only was Drd2 expression elevated, the expression of Drd1a and Adora2a also was above normal. This could reflect a complex cellular and network response to elevated expression of Drd2 in iSPNs or it could be a consequence of insertion effects that have nothing to do with Drd2 per se. Regardless of mechanism, there is a threshold for the effect as hemizygous $\mathrm{FVB} / \mathrm{N}$ mice were normal in every other assay.

\section{Other considerations in choosing a mouse strain}

C57BL/6 mice have been the most widely used inbred strain for genetically engineered mice. The $\mathrm{FVB} / \mathrm{N}$ strain has gained its popularity in this regard for several practical reasons (Hedrich and Bullock, 2004). First, its average litter size is significantly higher than that of other well known inbred strains. Second, fertilized eggs derived from $\mathrm{FVB} / \mathrm{N}$ mothers have very large and visually prominent pronuclei; this characteristic greatly facilitates the injection of DNA. Finally, the fraction of injected embryos that survive is also much greater with $\mathrm{FVB} / \mathrm{N}$ mice than other inbred strains.

A potential problem with inbred colonies is spontaneous mutation, which can lead to drift in the phenotype. There is a consensus that after 20 generations of brother-sister matings, a new inbred line is generated (Silva et al., 1997). For this reason, well characterized external breeders from established commercial source should be introduced into breeding programs on a regular basis and periodic genotyping performed.

Compared with these inbred strains, outbred strains generally have longer life spans, higher disease resistance, and higher overall reproductive performance (Hedrich and Bullock, 2004). Outbred SW mice are well known for their reproductive fitness. However, these outbred strains are genetically heterogeneous, making them problematic experimental subjects, particularly if the reproducibility of the response to a subtle intervention is important.

In summary, our studies demonstrate that commonly used inbred strains of mice (C57BL/6, FVB/N) that were hemizygous for the Drd2-eGFP BAC transgene had normal striatal gene expression, physiology, and motor behavior-arguing that these mice provide a reliable tool. Although the need to use hemizygous mice increases the costs of maintaining a colony, these added costs are offset by the experimental advantages afforded by the mice.

\section{References}

Ade KK, Janssen MJ, Ortinski PI, Vicini S (2008) Differential tonic GABA conductances in striatal medium spiny neurons. J Neurosci 28: $1185-1197$.

Ade KK, Wan Y, Chen M, Gloss B, Calakos N (2011) An improved BAC transgenic fluorescent reporter line for sensitive and specific identification of striatonigral medium spiny neurons. Front Syst Neurosci 5:32.

Albin RL, Young AB, Penney JB (1989) The functional anatomy of basal ganglia disorders. Trends Neurosci 12:366-375.

Albin RL, Young AB, Penney JB (1995) The functional anatomy of disorders of the basal ganglia. Trends Neurosci 18:63-64.

Andersen CL, Jensen JL, Ørntoft TF (2004) Normalization of real-time quantitative reverse transcription-PCR data: a model-based variance estimation approach to identify genes suited for normalization, applied to bladder and colon cancer data sets. Cancer Res 64:5245-5250.

Baker H, Joh TH, Reis DJ (1980) Genetic control of number of midbrain dopaminergic neurons in inbred strains of mice: relationship to size and neuronal density of the striatum. Proc Natl Acad Sci U S A 77:4369-4373.

Baker H, Joh TH, Ruggiero DA, Reis DJ (1983) Variations in number of dopamine neurons and tyrosine hydroxylase activity in hypothalamus of two mouse strains. J Neurosci 3:832-843.

Beal MF (2001) Experimental models of Parkinson's disease. Nat Rev Neurosci 2:325-334.

Bergman J, Madras BK, Spealman RD (1991) Behavioral effects of $D_{1}$ and $\mathrm{D}_{2}$ dopamine receptor antagonists in squirrel monkeys. J Pharmacol Exp Ther 258:910-917.

Bezard E, Przedborski S (2011) A tale on animal models of Parkinson's disease. Mov Disord 26:993-1002.

Boehme RE, Ciaranello RD (1981) Dopamine receptor binding in inbred mice: strain differences in mesolimbic and nigrostriatal dopamine binding sites. Proc Natl Acad Sci U S A 78:3255-3259.

Bookout AL, Cummins CL, Mangelsdorf DJ, Pesola JM, Kramer MF (2006) High-throughput real-time quantitative reverse transcription PCR. Curr Protoc Mol Biol Chapter 15:Unit 15.8.

Branco T, Staras K (2009) The probability of neurotransmitter release: variability and feedback control at single synapses. Nat Rev Neurosci 10:373-383.

Brodkin ES, Carlezon WA Jr, Haile CN, Kosten TA, Heninger GR, Nestler EJ (1998) Genetic analysis of behavioral, neuroendocrine, and biochemical parameters in inbred rodents: initial studies in Lewis and Fischer 344 rats and in A/J and C57BL/6J mice. Brain Res 805:55-68.

Castellano C, Zocchi A, Cabib S, Puglisi-Allegra S (1996) Strain-dependent effects of cocaine on memory storage improvement induced by posttraining physostigmine. Psychopharmacology 123:340-345.

Chan CS, Glajch KE, Gertler TS, Guzman JN, Mercer JN, Lewis AS, Goldberg AB, Tkatch T, Shigemoto R, Fleming SM, Chetkovich DM, Osten P, Kita H, Surmeier DJ (2011) HCN channelopathy in external globus pallidus neurons in models of Parkinson's disease. Nat Neurosci 14:85-92.

DeLong MR (1990) Primate models of movement disorders of basal ganglia origin. Trends Neurosci 13:281-285.

D’Este L, Casini A, Puglisi-Allegra S, Cabib S, Renda TG (2007) Comparative immunohistochemical study of the dopaminergic systems in two inbred mouse strains (C57BL/6J and DBA/2J). J Chem Neuroanat 33:67-74.

Durieux PF, Bearzatto B, Guiducci S, Buch T, Waisman A, Zoli M, Schiffmann SN, de Kerchove d'Exaerde A (2009) $\mathrm{D}_{2} \mathrm{R}$ striatopallidal neurons inhibit both locomotor and drug reward processes. Nat Neurosci 12:393-395.

Erwin VG, Womer DE, Campbell AD, Jones BC (1993) Pharmacogenetics of cocaine: II. Mesocorticolimbic and striatal dopamine and cocaine receptors in C57BL and DBA mice. Pharmacogenetics 3:189-196.

Flores G, Wood GK, Barbeau D, Quirion R, Srivastava LK (1998) Lewis and Fischer rats: a comparison of dopamine transporter and receptors levels. Brain Res 814:34-40. 
Fowler SC, Zarcone TJ, Vorontsova E (2001) Haloperiodol-induced microcatalepsy differs in CD-1, BALB/c, and C57BL/6 mice. Exp Clin Psychopharmacol 9:277-284.

Gerfen CR, Surmeier DJ (2011) Modulation of striatal projection systems by dopamine. Annu Rev Neurosci 34:441-466.

Gertler TS, Chan CS, Surmeier DJ (2008) Dichotomous anatomical properties of adult striatal medium spiny neurons. J Neurosci 28:1081410824.

Glajch KE, Fleming SM, Surmeier DJ, Osten P (2012) Sensorimotor assessment of the unilateral 6-hydroxydopamine mouse model of Parkinson's disease. Behav Brain Res 230:309-316.

Gong S, Zheng C, Doughty ML, Losos K, Didkovsky N, Schambra UB, Nowak NJ, Joyner A, Leblanc G, Hatten ME, Heintz N (2003) A gene expression atlas of the central nervous system based on bacterial artificial chromosomes. Nature 425:917-925.

Gong S, Kus L, Heintz N (2010) Rapid bacterial artificial chromosome modification for large-scale mouse transgenesis. Nat Protoc 5:1678-1696.

Grahame NJ, Cunningham CL (1995) Genetic differences in intravenous cocaine self-administration between C57BL/6J and DBA/2J mice. Psychopharmacology 122:281-291.

He M, Shippenberg TS (2000) Strain differences in basal and cocaineevoked dopamine dynamics in mouse striatum. J Pharmacol Exp Ther 293:121-127.

Hedrich HJ, Bullock GR (2004) The laboratory mouse. Amsterdam, Boston: Elsevier Academic.

Heintz N (2001) BAC to the future: the use of bac transgenic mice for neuroscience research. Nat Rev Neurosci 2:861-870.

Henderson ND, Turri MG, DeFries JC, Flint J (2004) QTL analysis of multiple behavioral measures of anxiety in mice. Behav Genet 34:267-293.

Jiao X, Paré WP, Tejani-Butt S (2003) Strain differences in the distribution of dopamine transporter sites in rat brain. Prog Neuropsychopharmacol Biol Psychiatry 27:913-919.

Kramer PF, Christensen CH, Hazelwood LA, Dobi A, Bock R, Sibley DR, Mateo Y, Alvarez VA (2011) Dopamine $\mathrm{D}_{2}$ receptor overexpression alters behavior and physiology in Drd2-EGFP mice. J Neurosci 31:126-132.

Kreitzer AC, Malenka RC (2007) Endocannabinoid-mediated rescue of striatal LTD and motor deficits in Parkinson's disease models. Nature 445:643-647.

McNamara RK, Levant B, Taylor B, Ahlbrand R, Liu Y, Sullivan JR, Stanford K, Richtand NM (2006) C57BL/6J mice exhibit reduced dopamine $\mathrm{D}_{3}$ receptor-mediated locomotor-inhibitory function relative to DBA/2J mice. Neuroscience 143:141-153.

Miner LL (1997) Cocaine reward and locomotor activity in C57BL/6J and $129 /$ SvJ inbred mice and their $F_{1}$ cross. Pharmacol Biochem Behav 58:25-30.

Morice E, Denis C, Giros B, Nosten-Bertrand M (2004) Phenotypic expression of the targeted null-mutation in the dopamine transporter gene varies as a function of the genetic background. Eur J Neurosci 20:120-126.

Nelson AB, Hang GB, Grueter BA, Pascoli V, Luscher C, Malenka RC, Kreitzer AC (2012) A comparison of striatal-dependent behaviors in wildtype and hemizygous Drdla and Drd2 BAC transgenic mice. J Neurosci 32:9119-9123.

Ng GY, O'Dowd BF, George SR (1994) Genotypic differences in brain dopamine receptor function in the DBA/2J and C57BL/6J inbred mouse strains. Eur J Pharmacol 269:349-364.
Patel N, Hitzemann B, Hitzemann R (1998) Genetics, haloperidol, and the Fos response in the basal ganglia: a comparison of the C57BL/6J and DBA/2J inbred mouse strains. Neuropsychopharmacology 18:480-491.

Pfaffl MW, Tichopad A, Prgomet C, Neuvians TP (2004) Determination of stable housekeeping genes, differentially regulated target genes and sample integrity: BestKeeper-Excel-based tool using pair-wise correlations. Biotechnol Lett 26:509-515.

Rogaeva A, Ou XM, Jafar-Nejad H, Lemonde S, Albert PR (2007) Differential repression by freud-1/CC2D1A at a polymorphic site in the dopamine- $\mathrm{D}_{2}$ receptor gene. J Biol Chem 282:20897-20905.

Ross RA, Judd AB, Pickel VM, Joh TH, Reis DJ (1976) Strain-dependent variations in number of midbrain dopaminergic neurones. Nature 264:654-656.

Sanghera MK, Crespi F, Martin KF, Heal DJ, Buckett WR, Marsden CA (1990) Biochemical and in vivo voltammetric evidence for differences in striatal dopamine levels in inbred strains of mice. Neuroscience 39:649-656.

Schmittgen TD, Livak KJ (2008) Analyzing real-time PCR data by the comparative $\mathrm{C}_{\mathrm{T}}$ method. Nat Protoc 3:1101-1108.

Severson JA, Randall PK, Finch CE (1981) Genotypic influences on striatal dopaminergic regulation in mice. Brain Res 210:201-215.

Siegert S, Scherf BG, Del Punta K, Didkovsky N, Heintz N, Roska B (2009) Genetic address book for retinal cell types. Nat Neurosci 12:1197-1204.

Silva AJ, Simpson EM, Takahashi JS, Lipp HP, Nakanishi S, Wehner JM, Giese KP, Tully T, Abel T, Chapman PF, Fox K, Grant S, Itohara S, Lathe R, Mayford M, McNamara JO, Morris RJ, Picciotto M, Roder J, Shin HS, et al. (1997) Mutant mice and neuroscience: recommendations concerning genetic background. Neuron 19:755-759.

Silver N, Best S, Jiang J, Thein SL (2006) Selection of housekeeping genes for gene expression studies in human reticulocytes using real-time PCR. BMC Mol Biol 7:33.

Sved AF, Baker HA, Reis DJ (1984) Dopamine synthesis in inbred mouse strains which differ in numbers of dopamine neurons. Brain Res 303:261-266.

Taché Y, Mönnikes H, Bonaz B, Rivier J (1993) Role of CRF in stress-related alterations of gastric and colonic motor function. Ann N Y Acad Sci 697:233-243.

Vandesompele J, De Preter K, Pattyn F, Poppe B, Van Roy N, De Paepe A, Speleman F (2002) Accurate normalization of real-time quantitative RT-PCR data by geometric averaging of multiple internal control genes. Genome Biol 3:RESEARCH0034.

Womer DE, Jones BC, Erwin VG (1994) Characterization of dopamine transporter and locomotor effects of cocaine, GBR 12909, epidepride, and SCH 23390 in C57BL and DBA mice. Pharmacol Biochem Behav 48:327-335

Zamudio S, Fregoso T, Miranda A, De La Cruz F, Flores G (2005) Strain differences of dopamine receptor levels and dopamine related behaviors in rats. Brain Res Bull 65:339-347.

Zocchi A, Orsini C, Cabib S, Puglisi-Allegra S (1998) Parallel straindependent effect of amphetamine on locomotor activity and dopamine release in the nucleus accumbens: an in vivo study in mice. Neuroscience 82:521-528.

Zucker RS, Regehr WG (2002) Short-term synaptic plasticity. Annu Rev Physiol 64:355-405. 